\title{
Cyanoacrylate tissue adhesives - effective securement technique for intravascular catheters: in vitro testing of safety and feasibility
}

\author{
G. SIMONOVA*, C. M. RICKARD†, K. R. DUNSTER $\ddagger$ D. J. SMYTH§, D. MCMILLAN**, \\ J. F. FRASER $\dagger \dagger$ \\ Critical Care Research Group, University of Queensland and Prince Charles Hospital, Brisbane, Queensland, Australia
}

\begin{abstract}
SUMMARY
Partial or complete dislodgement of intravascular catheters remains a significant problem in hospitals despite current securement methods. Cyanoacrylate tissue adhesives (TA) are currently used to close skin wounds as an alternative to sutures. These adhesives have high mechanical strength and can remain in situ for several days. This study investigated in vitro use of TAs in securing intravascular catheters (IVC). We compared two adhesives for interaction with IVC material, comparing skin glues with current securement methods in terms of their ability to prevent IVC dislodgement and to inhibit microbial growth. Two TAs (Dermabond ${ }^{\circledR}$, Ethicon Inc. and Histoacryl ${ }^{\oplus}$, B. Braun) and three removal agents (Remove ${ }^{\mathrm{TM}}$, paraffin and acetone) were tested for interaction with IVC material by use of tensile testing. TAs were also compared against two polyurethane (standard and bordered) dressings (Tegaderm $^{\mathrm{TM}} 1624$ and 1633, 3M Australia Pty Ltd) and an external stabilisation device (Statlock ${ }^{\circledast}$, Bard Medical, Covington) against control (unsecured IVCs) for ability to prevent pull-out of $16 \mathrm{G}$ peripheral IVCs from newborn fresh porcine skin. Agar media containing $\mathrm{pH}$-sensitive dye was used to assess antimicrobial properties of TAs and polyurethane dressings to inhibit growth of Staphylococcus aureus and Staphylococcus epidermidis. Neither TA weakened the IVCs $(P>0.05)$. Of removal agents, only acetone was associated with a significant decrease in IVC strength $(P<0.05)$. Both TAs and Statlock significantly increased the pull-out force $(P<0.01)$. TA was quick and easy to apply to IVCs, with no irritation or skin damage noted on removal and no bacterial colony growth under either TA.
\end{abstract}

Key Words: intravascular catheter, dressings, Dermabond, Histoacryl, pull-out force, antibacterial effect

Intravascular catheter (IVC) insertion is the most common invasive procedure performed in hospitals each year, with $\sim 150$ million used in the $\mathrm{USA}^{1-3}$ and $\sim 14$ million in Australia annually, $y^{4,5}$ Good securement of the IVC to the skin is necessary to ensure that the device does not dislodge and either

\footnotetext{
* MSc, Research Assistant and Biochemical Engineer, National Health and Medical Research Council Centre of Research Excellence in Nursing Interventions, Griffith University,

$\dagger$ RN, PhD, Professor, National Health and Medical Research Council Centre of Research Excellence in Nursing Interventions, Griffith University.

\$ BSc, Research Fellow, Medical Engineering, Queensland University of Technology.

$\S$ PhD, Research Fellow, Bacterial Pathogenesis Laboratory, Queensland Institute of Medical Research.

**PhD, Senior Research Officer, Bacterial Pathogenesis Laboratory, Queensland Institute of Medical Research.

$\dagger \dagger \mathrm{MB}, \mathrm{ChB}, \mathrm{PhD}$, MRCP, FRCA, FFARCSI, FCICM, Director, Critical Care Research Group, Prince Charles Hospital.

Address for correspondence: Ms G. Simonova. Email: g.simonova@ uq.edu.au

Accepted for publication on February 20, 2012.
}

fall out, or move out of the vein and into the surrounding tissue. This can occur via overt movement and pressure on the external body of the IVC, 'drag' from infusion tubing, or accidental 'catching' on environmental structures such as clothing or bedclothes ${ }^{6}$. In addition, effective securement also minimises IVC micro-motion ('pistoning') within the vessel, which irritates the vein wall, precipitating inflammation presenting as pain, swelling and occlusion causing IVC failure, while also encouraging entry of skin-borne bacteria ${ }^{7,8}$. Millions of dollars are spent on dressings to secure IVCs to the skin each year ${ }^{8}$, yet failure rates of IVCs are still high, affecting up to $92 \%$ of patients receiving therapy ${ }^{9-11}$. Given that device failure always necessitates removal and reinsertion of a new IVC, which negatively affects a patient's ability to receive prescribed medical therapy and increases pain for reinsertion 6 , there is a need to improve current securement practices. This is particularly pertinent as most failures are likely to be preventable 
through better securement, since currently IVC movement leads to IVCs becoming dislodged or falling out ${ }^{12,13}$. Despite this, study of IVC securement has received little research attention ${ }^{7,14}$.

The earliest, and still used IVC securement approach was simple tape or gauze-tape, with plastic film dressings becoming prominent in the $1980 \mathrm{~s}^{15,16}$. Several earlier studies compared gauzetape to film dressings and after an early systematic review found standard polyurethane (SPU) to have higher infection risk $^{17}$, modern polyurethanes were developed which are commercially-made, transparent and semi-permeable (to oxygen, carbon dioxide and water vapour) ${ }^{9}$. SPU have been the standard/usual care for many years, although two new approaches have recently entered the market: bordered polyurethane and external stabilisation devices. Bordered polyurethanes retain the central poly-urethane component of SPUs, with an added external adhesive border of foam or cloth fabric (e.g. Tegaderm ${ }^{\mathrm{TM}}$ Advanced, 3M Australia Pty Ltd, Pymble, NSW). External stabilisation devices are used in addition to SPUs and have a large adhesive footplate under-lying a pad with an IVC-locking clasp (e.g. Statlock ${ }^{\circledast}$, Bard Medical, Covington, GA, USA and Hubguard ${ }^{\circledR}$, CENTURION Medical Products, Williamston, MI, USA); theoretically they reduce movement, kinking and flow impedance? Recent studies have suggested better results with both bordered polyurethanes and silver sulfadiazines, but these are limited by being manufacturer-funded, of small sample size and/or non-randomised design ${ }^{8,11,14,18-22}$. To our knowledge, no rigorous, independent testing has been reported in the literature.

Tissue adhesive (TA) is medical grade 'superglue' (cyanoacrylate) used mainly to close skin lacerations/ wounds as an alternative to sutures and staples, but also for repair of gastric varices, inguinal hernias, bones, tendons and retinal detachments ${ }^{23-34}$. TA has been shown to have haemostatic properties that may reduce post-insertion bleeding, haematoma formation and associated infection risk. Until recently, TA to secure IVCs had not been reported, however recent (2007 to 2008) case reports suggest TA may be an ideal product for IVC securement $^{35,36}$. In these, TA was completely successful in preventing $\sim 100$ similar devices (epidural and central venous devices) from falling out, with no skin reactions or mechanical problems ${ }^{35,36}$. The reported reduction in epidural device accidental removal was from 12.3 to $3.8 \%$. TA also appears to have superior infection prevention properties, with in vitro work showing TA to have excellent inhibition of all Gram-positive organisms, the most common causes of IVC-associated infection including Staphylococcus aureus ${ }^{37}$. Skin glue has a high mechanical strength and can remain in place for five to 10 days $^{36}$, which exceeds the average dwell time of an IVC (four to five days) ${ }^{10}$. The TA sloughs off slowly over this time and can be 'topped up' if longer use is needed. It can be removed at any time with commercial adhesive removers or petroleum jelly. TA forms an occlusive woundhealing environment and antimicrobial properties have been reported, with reduced bacterial wound counts $^{38}$ and reduced infection rates ${ }^{39-41}$. Taking all of this into consideration, it is possible that TA may be an important contributor to reducing IVC failure, by reducing 'pistoning' and accidental removal, with additional benefits being infection prevention and patient comfort.

Prior to widespread patient use it is necessary to know whether the mechanical strength of the IVC itself is chemically compatible with both TAs and the solvents used to remove TA when the IVC is removed. Similarly, it is unknown whether the force required to remove a TA-secured IVC from skin is below the point at which the IVC itself would fail, rather than damaging the skin on removal. With normal patient activity, the movement of an IVC with respect to the skin is complex and not easily modelled in a mechanical system. A tensile pull-out model was chosen to ensure reproducibility and allow comparison between the securement devices chosen. The progressive weakening of the securement that may occur with normal patient activity was not studied.

This study sought to assess the compatibility of IVC with skin glues and removal agents, and to compare the pull-out force of IVC fixation by Dermabond (Ethicon Inc., Puerto Rico) and Histoacryl (B. Braun, Tuttlingen, Germany) with those of more conventional methods, being standard polyurethane dressing, bordered polyurethane dressing and external stabilisation device. In addition, the study aimed to model bacterial migration at the skin/device interface and the growth under each securement technique.

\section{MATERIALS AND METHODS}

There were three components to this study: 1) assessment of chemical compatibility between TAs and TA removal agents and IVCs; 2) comparison of pull-out strength of TA and current dressing methods against control; and 3) assessment of microbiological qualities of TA against current dressing methods. 


\section{Assessment of chemical compatibility}

The chemical compatibility of IVCs (16GA 1.16IN $[1.7 \times 30 \mathrm{~mm}]$ Insyte $^{\mathrm{TM}}$ Autoguard $^{\mathrm{TM}} \quad[\mathrm{BD}$, Franklin Lakes, NJ, USA], made of BD Vialon), with two cyanoacrylate TAs: Dermabond and Histoacryl, and three removal agents: paraffin, acetone and Remove $^{\mathrm{TM}}$ adhesive removal wipes (Smith \& Nephew, Canada) was assessed by measuring the tensile strength of IVCs after exposure to these solutions on the central $1 \mathrm{~cm}$ of the IVC for one hour, followed by mechanical testing. The tensile strength was measured at room temperature using an Instron 5567 (Instron Pty Ltd., High Wycombe, UK) universal tensile testing machine at a crosshead speed of $250 \mathrm{~mm} /$ minute. The maximal force $[\mathrm{N}]$ was recorded for every test ( $n=6$ per group) of each group. Mean and SD were calculated.

\section{Assessment of pull-out forces}

For comparative testing, the hind legs of term newborn piglets obtained at caesarean section were used immediately after harvesting. The legs were removed at the hip, scrubbed with paper towel and hair was then removed with a surgical clipper.

Hind legs were sourced post-mortem from an existing research project using piglets. The chief investigators of the donor projects agreed to share tissue in order to reduce the overall number of animals required for research. "Tissue use notification" was submitted and confirmed by the Griffith University and Queensland University of Technology Research Ethics Units (Approval number 1100000132).

Blood/solution drip-sets with a Luer Lock adaptor (Baxter Healthcare Pty, Old Toongabbie, NSW) were attached to the IVCs (16GA 1.16IN $[1.7 \times 30 \mathrm{~mm}]$ Insyte Autoguard) and cut to $\sim 10 \mathrm{~cm}$ long. IVCs $(n=12)$ were then inserted into the piglet legs and secured with either 2-octyl-cyanoacrylate (Dermabond) or butyl-cyanoacrylate (Histoacryl). A $0.25 \mathrm{ml}$ aliquot of freshly opened Dermabond or Histoacryl was applied each time under both the catheter-hub interface and the hub portion, and allowed to dry for 30 minutes. An additional eight IVCs were secured to the piglet leg, using standard or bordered polyurethane dressings (Tegaderm $1624 \mathrm{~W}$ and Tegaderm $1633 \mathrm{~W}$ respectively) and three IVCs were secured with an external stabilisation device (Statlock IV Ultra, Bard Medical, used without additional dressing). All dressings and external stabilisation devices were applied as per the manufacturers' instructions. Five control IVCs were inserted without any securement.
The pull-out force, defined here as the tensile force $(\mathrm{N})$ required to produce bond failure, was measured using an Instron 5567 under the same conditions as described above. All data were analysed in a one-way analysis of variance, followed by a post hoc Bonferroni test. The Bartlett test was used to verify assumptions. Statistical significance was determined at $P \leq 0.05$.

\section{Microbiological test methods}

We tested two Gram-positive bacterial species, Staphylococcus aureus and Staphylococcus epidermidis, which are part of normal skin microflora and most commonly associated with IVCrelated blood stream infections. Agar containing a pH-sensitive dye (bromocresol purple) was used according to the method described by Bhende et $\mathrm{al}^{42}$. The basis of the microbiological test relies on $\mathrm{pH}$ indicator agar that changes from purple to yellow when actively growing bacteria produce organic acids.

IVCs (20GA 1.16IN $[1.1 \times 30 \quad \mathrm{~mm}]$ Insyte catheter) was inserted aseptically into the agar at an approximately $30^{\circ}$ angle and cyanoacrylate tissue adhesive was applied to the agar surface at the insertion point and allowed to dry at room temperature. Four IVCs were secured with each TA and with each polyurethane dressing per species. Four IVCs were inserted per plate when TA was applied, but only one per plate was used when a physical dressing was applied for fixation. For TAsecured IVCs, either half a vial of Dermabond or a quarter vial of Histoacryl was used at each insertion point and, in all cases, a single-layered film was applied. Inoculation of test bacteria was performed by pipetting a $5 \mu \mathrm{l}$ aliquot of the stock inoculums around the edges of the glue and $10 \mu \mathrm{l}$ around the dressing edges. Plates were incubated for 18 or 72 hours at $37^{\circ} \mathrm{C}$ and scored by colony counts.

\section{RESULTS}

\section{Chemical compatibility}

IVC tensile strength was not reduced with either of the TAs nor with two of the solvent agents $(P>0.05)$. Acetone was the only tested product which weakened the IVC significantly $(P<0.05)$. The chemical compatibility results are summarised in Table 1.

\section{Pull-out forces}

The mechanical strength for each group is depicted in Figure 1. Neither the standard polyurethane dressing nor the bordered polyurethane dressing significantly increased the pull-out force 
compared to control $(P>0.05)$. However, both cyanoacrylate TAs and the external stabilisation device significantly increased the pull-out force (Dermabond and Statlock $P<0.01$; Histoacryl $P<0.001$ ), although applying additional dressings to these adhesives did not change the pull-out force considerably. Securement with Histoacryl resulted in a bond that was twice as strong as Dermabond, and was four times as strong as the standard care dressings (standard polyurethane dressing). After

TABLE 1

Assessment of tissue adhesives and removal agents for chemical compatibility with IVCs

\begin{tabular}{ll}
\hline & Tensile strength $(\mathrm{N})$, mean \pm SD \\
\hline Control & $45.68 \pm 1.24$ \\
Tissue adhesives & \\
Dermabond & $45.69 \pm 1.09$ \\
Histoacryl & $42.35 \pm 1.96$ \\
Removal agents & \\
Remove $^{\mathrm{TM}}$ & $50.23 \pm 2.44$ \\
Paraffin $_{\text {Acetone }}$ & $46.17 \pm 2.28$ \\
\hline
\end{tabular}

Data expressed as mean \pm SD. The control was a plain intravascular catheter (IVC) without use of any chemical agent. ${ }^{*} P<0.05$ control vs chemical agent. these tests, no visible damage was observed on the skin surface with visual inspection.

\section{Microbiological results}

Bacterial growth was observed surrounding TA and all tested products at 18 hours post-inoculation. However, there was no visible growth under the TA, and no penetration of bacterial along the IVC tunnel (in agar) at either 18 or 72 hours. For both transparent dressings, no growth was observed at the entry point or along the IVC at 18 hours, although growth was observed under and surrounding the products. At 72 hours, bacterial growth was also observed at the IVC entry point, and along the IVC tract for those secured with polyurethane dressings. See Table 2 and Figure 2.

\section{DISCUSSION}

To our knowledge, there has been no previous in vitro study undertaken to assess the suitability of TAs for the securement of IVCs. TAs are currently used in clinical practice for effective wound closure, but are not in general use for IVC securement. In a small case series report by Wilkinson et al, Histoacryl was completely successful in preventing epidural and central venous catheters from falling out with no skin reactions or mechanical problems with catheters ${ }^{35,43}$. Another small case study by

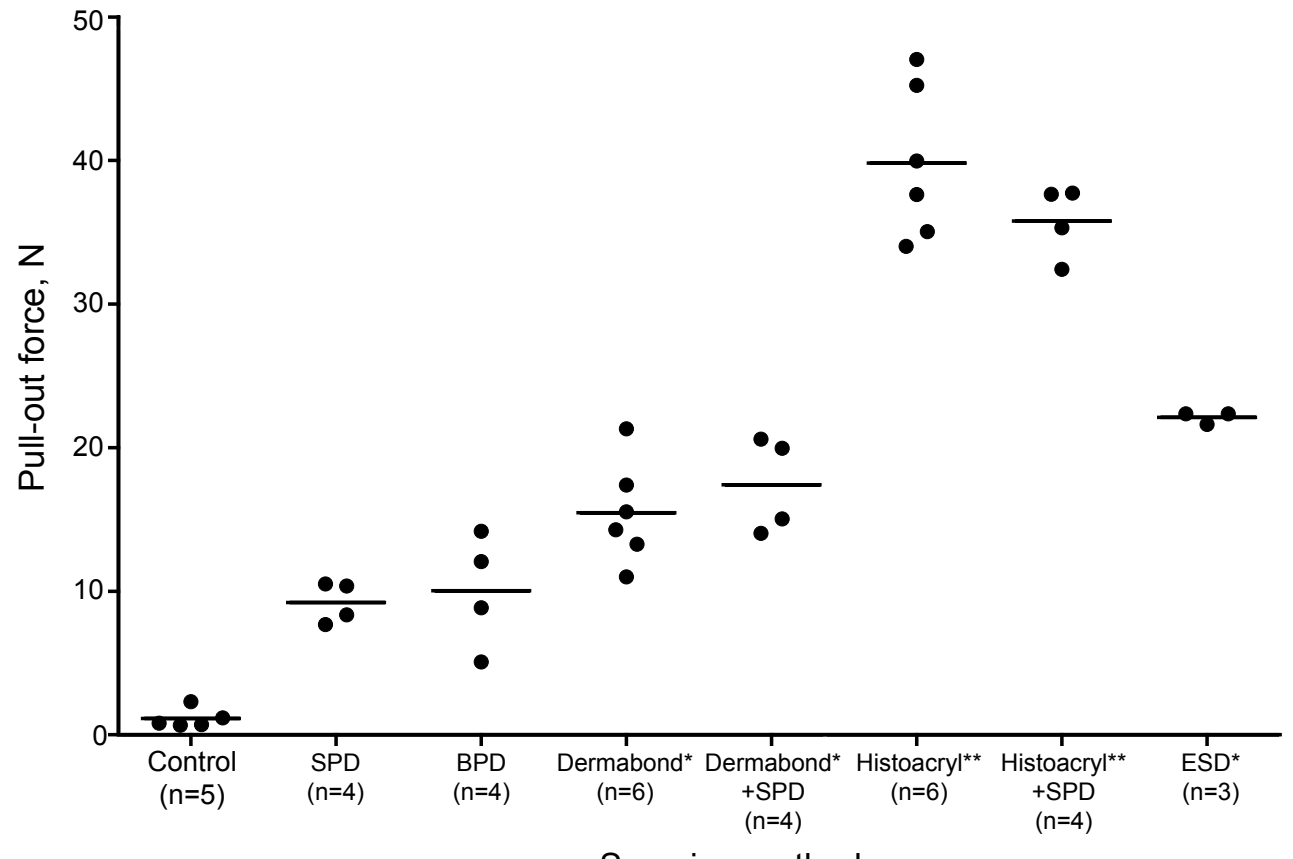

Securing method

FIGURE 1: Mechanical tests results. IVCs were inserted into the hind leg of piglets, and secured with TA, dressing or external stabilisation device. Control defined as plain IVC without securement. The pull-out force $(\mathrm{N})$ required to produce bond failure was determined by using an Instron 5567 universal tensile force machine. SPD=standard polyurethane dressing, $\mathrm{BPD}=$ bordered polyurethane dressing,

$\mathrm{ESD}=$ external stabilisation device. ${ }^{*} P<0.01$ control vs used securing method. ${ }^{*} P<0.001$ control vs used securing method 
TABLE

Bacterial growth surrounding IVCs and fixation devices*

\begin{tabular}{|c|c|c|c|c|c|c|c|c|c|}
\hline & \multirow[b]{2}{*}{ Fixation method } & \multicolumn{4}{|c|}{18 hours } & \multicolumn{4}{|c|}{72 hours } \\
\hline & & $\begin{array}{l}\text { Entry } \\
\text { point } \dagger\end{array}$ & $\begin{array}{l}\text { IVC } \\
\text { tract } \$\end{array}$ & $\begin{array}{l}\text { Beneath } \\
\text { fixation } \\
\text { device }\end{array}$ & $\begin{array}{l}\text { Around } \\
\text { fixation } \\
\text { device }\end{array}$ & $\begin{array}{l}\text { Entry } \\
\text { point }\end{array}$ & $\begin{array}{l}\text { IVC } \\
\text { tract }\end{array}$ & $\begin{array}{l}\text { Beneath } \\
\text { fixation } \\
\text { device }\end{array}$ & $\begin{array}{l}\text { Around } \\
\text { fixation } \\
\text { device }\end{array}$ \\
\hline \multirow{5}{*}{ S. aureus } & Unfixed $(n=4)$ & + & + & NA & NA & + & + & NA & NA \\
\hline & Dermabond $(n=8)$ & - & - & - & + & - & - & - & + \\
\hline & Histoacryl $(\mathrm{n}=8)$ & - & - & - & + & - & - & - & + \\
\hline & Tegaderm $1624(n=8)$ & - & - & + & + & + & + & + & + \\
\hline & Tegaderm $1633(n=4)$ & - & - & + & + & + & + & + & + \\
\hline \multirow{5}{*}{ S. epidermidis } & Unfixed $(n=4)$ & + & + & NA & NA & + & + & NA & NA \\
\hline & Dermabond $(n=4)$ & - & - & - & + & - & - & - & + \\
\hline & Histoacryl $(n=4)$ & - & - & - & + & - & - & - & + \\
\hline & Tegaderm $1624(n=4)$ & - & - & + & + & + & + & + & + \\
\hline & Tegaderm $1633(n=4)$ & - & - & + & + & + & + & + & + \\
\hline
\end{tabular}

"+" or "-“; growth or absence of growth at 18 and 72 hours. * Fixation device; refers to both TA and physical dressings. $\dagger$ Entry point; point at which the IBC enters the agar. $\$$ IVC tract; refers to growth adjacent the IVC body within the agar. IVC=intravascular catheters, NA=not applicable, $S$. aureus =Staphylococcus aureus,$S$ epidermidis $=$ Staphylococcus epidermidis.

A)

$18 \mathrm{~h}$ incubation

B)

C)

FIGURE 2: Microbiological test results. A) Positive control with $S$. aureus on $\mathrm{pH}$ selective agar. B) IVC secured with Dermabond ${ }^{\circledast}$ and inoculated with 51 each $S$. aureus around the adhesives. C) IVC secured with bordered type of polyurethane dressing and inoculated with $10 \mu \mathrm{l} \mathrm{S}$. aureus around the edge of the tape. IVC=intravascular catheter. 
Klein et al reported similar effective securement using Dermabond on peripheral nerve catheters ${ }^{44}$. Although these reports suggest that TA may be a suitable and superior alternative to current dressing methods for IVCs, there is no clinical trial data assessing the safety and efficacy of this method. In vitro data is a vital first phase in exploring the suitability of any new medical device or procedure, before exposing patients to its use on a broad scale.

The present study indicates that either Dermabond or Histoacryl cyanoacrylate provide a reliable and superior method of peripheral IVC fixation in vitro. Neither adhesive affected the catheter material, and both required a far greater pullout force than non-fixed controls and current securement dressing methods. Further our findings also indicate that TAs and dressings used in conjunction do not increase strength of securement, over TA alone. Dressing implementation is, therefore, unnecessary on top of a TA in terms of strengthening the bond. Recently developed external stabilisation devices, such as Statlock, also offer an alternative securement solution but, compared to TA, have the downside of catheter specificity whereby hospitals need to stock numerous different product versions associated with the different types and brands of IVCs used.

In this study, IVC fixation was significantly more effective with Histoacryl than with Dermabond. Strength and many other physical properties of the cyanoacrylate adhesives are directly related to the structure of the alkyl side-chain, and minor changes in the composition may explain the differences in strength observed ${ }^{45}$. Short, straight-chain derivatives (ethyl or butyl cyanoacrylate) form stronger bonds compared to the long-chain derivatives (e.g. octylcyanoacrylate). The side-chain is also responsible for the setting time and degradation rate of the polymer.

The results of this study reinforce the hypothesis that cyanoacrylate tissue adhesives are an effective barrier to Gram-positive bacterial penetration in the in vitro model ${ }^{37-41}$. Compared to dressings, it successfully prevented against organism growth down the IVC tract and therefore may be likely to decrease the probability of bloodstream infections when used in patients.

Limitations of this study include the use of a newborn porcine skin model to assess tensile forces, which may not adequately represent the experience in human hospital patients. Our application of TAs and removal products on IVCs occurred after one hour, and different results may have been seen after longer periods. Despite these issues, previous case series in human patients have not reported any issues with IVC degradation.

In conclusion, this preliminary data supports case reports in the literature about the potentially suitable use of cyanoacrylate tissue adhesives for IVC securement. More detailed assessment of the product for this purpose is warranted, including clinical trials that should assess outcomes such as IVC failure due to accidental removal, infiltration and infection, as well as cost-effectiveness and patient comfort.

\section{ACKNOWLEDGEMENTS}

This work was supported in part by a grant from the Prince Charles Hospital Foundation (Application No. NR2010-205). Further financial support of the study came from the Critical Care Research Group, the Prince Charles Hospital, and from the Intravascular Device Research Group, Griffith University. The authors express their gratitude to Dr Barbara Lingwood (Perinatal Research Centre, the University of Queensland) for the provision of the piglet legs.

\section{REFERENCES}

1. Mermel LA, Allon M, Bouza E, Craven DE, Flynn P, O'Grady $\mathrm{NP}$ et al. Clinical practice guidelines for the diagnosis and management of intravascular catheter-related infection: 2009 Update by the Infectious Diseases Society of America. Clin Infect Dis 2009; 49:1-45.

2. Wenzel RP, Edmond MB. Team-based prevention of catheterrelated infections. N Engl J Med 2006; 355:2781-2783.

3. Zingg W, Pittet D. Peripheral venous catheters: an underevaluated problem. Int J Antimicrob Agents 2009; 34:38-42.

4. Australian Bureau of Statistics: Australian Historical Population Statistics, 2008. In. Canberra: AIHW; 2008.

5. Maki DG. Infections due to infusion therapy. In: Bennett JV, Brachmann PS, eds. Hospital Infections, 3rd ed. Boston: Little Brown and Co. Inc. 1992. p. 849-898.

6. Naimer SA, Temira F. Evaluation of techniques for intravenous catheter and tubing fixation. Mil Med 2004; 169:79-81.

7. Frey AM, Schears GJ. Why are we stuck on tape and suture? A review of catheter securement devices. J Infus Nurs 2006; 29:34-38.

8. Royer T. Improving short peripheral IV outcomes: a clinical trial of two securement methods. J Assoc Vasc Access 2003; 8:45-49.

9. Maki DG, Ringer M. Evaluation of dressing regimens for prevention of infection with peripheral intravenous catheters. Gauze, a transparent polyurethane dressing, and an iodophortransparent dressing. JAMA 1987; 258:2396-2403.

10. Rickard CM, McCann D, Munnings J, McGrail MR. Routine resite of peripheral intravenous devices every 3 days did not reduce complications compared with clinically indicated resite: a randomised controlled trial. BMC Med 2010; 8:53.

11. Smith B. Peripheral intravenous catheter dwell times: a comparison of 3 securement methods for implementation of a 96-hour scheduled change protocol. J Infus Nurs 2006; 29:1417. 
12. Durie M, Beckmann U, Gillies DM. Incidents relating to arterial cannulation as identified in 7,525 reports submitted to the Australian incident monitoring study (AIMS-ICU). Anaesth Intensive Care 2002; 30:60-65.

13. Van Gessel H, McCavana C. Increased incidence of infections associated with peripheral IV cannulae: recognition, investigation, interventions. Australian Infection Control 2006; 11:39$40,42,45$.

14. Sheppard K, LeDesma M, Morris NL, O'Connor K. A prospective study of two intravenous catheter securement techniques in a skilled nursing facility. J Intraven Nurs 1999; 22:151-156.

15. Campbell H, Carrington M. Peripheral i.v. cannula dressings: advantages and disadvantages. Br J Nurs 1999; 8:1420-1422, 1424-1427.

16. Smith B, Royer TI. New standards for improving peripheral i.v. catheter securement. Nursing 2007; 37:72-74.

17. Hoffmann KK, Weber DJ, Samsa GP, Rutala WA. Transparent polyurethane film as an intravenous catheter dressing. A metaanalysis of the infection risks. JAMA 1992; 267:2072-2076.

18. Bausone-Gazda D, Lefaiver CA, Walters S-A. A randomized controlled trial to compare the complications of 2 peripheral intravenous catheter-stabilization systems. J Infus Nurs 2010; 33:371-384.

19. Callaghan S, Copnell B, Johnston L. Comparison of two methods of peripheral intravenous cannula securement in the pediatric setting. J Infus Nurs 2002; 25:256-264.

20. Needham R, Strehle E-M. Evaluation of dressings used with local anaesthetic cream and for peripheral venous cannulation. Paediatr Nurs 2008; 20:34-36.

21. Schears GJ. Summary of product trials for 10,164 patients: comparing an intravenous stabilizing device to tape. J Infus Nurs 2006; 29:225-231.

22. Wood D. A comparative study of two securement techniques for short peripheral intravenous catheters. J Intraven Nurs 1997; 20:280-285.

23. Aukerman DF, Sebastianelli WJ, Nashelsky J. Clinical inquiries. How does tissue adhesive compare with suturing for superficial lacerations? J Fam Pract 2005; 54:378.

24. Singer AJ, Thode HC Jr. A review of the literature on octylcyanoacrylate tissue adhesive. Am J Surg 2004; 187:238-248.

25. Amarante MT, Constantinescu MA, O'Connor D, Yaremchuk MJ. Cyanoacrylate fixation of the craniofacial skeleton: an experimental study. Plast Reconstr Surg 1995; 95:639-646.

26. Ayan I, Colak M, Comelekoglu U, Milcan A, Ogenler O, Oztuna V et al. Histoacryl glue in meniscal repairs (a biomechanical study). Int Orthop 2007; 31:241-246.

27. Bresnahan KA, Howell JM, Wizorek J. Comparison of tensile strength of cyanoacrylate tissue adhesive closure of lacerations versus suture closure. Ann Emerg Med 1995; 26:575-578.

28. King ME, Kinney AY. Tissue adhesives: a new method of wound repair. Nurse Pract 1999; 24:73-74.

29. Matthews SC. Tissue bonding: the bacteriological properties of a commercially-available cyanoacrylate adhesive. Br J Biomed Sci 1993; 50:17-20.
30. Nipshagen MD, Hage JJ, Beekman WH. Use of 2-octylcyanoacrylate skin adhesive (Dermabond) for wound closure following reduction mammaplasty: a prospective, randomized intervention study. Plast Reconstr Surg 2008; 122:10-18.

31. Oztuna V, Yilmaz A, Yilmaz C, Eskandari MM, Ayan I, Milcan A et al. [The use of N-butyl-2-cyanoacrylate (Histoacryl) in primary tendon repair: a biomechanical study with sheep flexor tendons]. Acta Orthop Traumatol Turc 2005; 39:258-262.

32. Shapiro AJ, Dinsmore RC, North JH Jr. Tensile strength of wound closure with cyanoacrylate glue. Am Surg 2001; 67:1113-1115.

33. Souza EC, Fitaroni RB, Januzelli DM, Macruz HM, Camacho JC, Souza MR. Use of 2-octyl cyanoacrylate for skin closure of sternal incisions in cardiac surgery: observations of microbial barrier effects. Curr Med Res Opin 2008; 24:151-155.

34. Steiner Z, Mogilner J. Histoacryl vs Dermabond cyanoacrylate glue for closing small operative wounds. Harefuah 2000; 139:409-411, 496.

35. Wilkinson JN, Fitz-Henry J. Securing epidural catheters with Histoacryl glue. Anaesthesia 2008; 63:324.

36. Wilkinson JN, Sheikh N, Jayamaha J. Tissue adhesive as an alternative to sutures for securing central venous catheters. Anaesthesia 2007; 62:969-970.

37. Wilkinson JN, Chikhani M, Mortimer K, Gill SJ. The antimicrobial effect of Histoacryl skin adhesive. Anaesthesia 2008; 63:1382-1384.

38. Howell JM, Bresnahan KA, Stair TO, Dhindsa HS, Edwards BA. Comparison of effects of suture and cyanoacrylate tissue adhesive on bacterial counts in contaminated lacerations. Antimicrob Agents Chemother 1995; 39:559-560.

39. Bhende S, Rothenburger S, Spangler DJ, Dito M. In vitro assessment of microbial barrier properties of Dermabond topical skin adhesive. Surg Infect (Larchmt) 2002; 3:251-257.

40. Eiferman RA, Snyder JW. Antibacterial effect of cyanoacrylate glue. Arch Ophthalmol 1983; 101:958-960.

41. Narang U, Mainwaring L, Spath G, Barefoot J. In-vitro analysis for microbial barrier properties of 2-octyl cyanoacrylatederived wound treatment films. J Cutan Med Surg 2003; 7:1319.

42. Bhende S, Rothenburger S, Spangler DJ, Dito M. In vitro assessment of microbial barrier properties of Dermabond topical skin adhesive. Surg Infect (Larchmt) 2002; 3:251-257.

43. Wilkinson JN, Sheikh N, Jayamaha J. Tissue adhesive as an alternative to sutures for securing central venous catheters. Anaesthesia 2007; 62:969-970.

44. Klein SM, Nielsen KC, Buckenmaier CC 3rd, Kamal ASA, Rubin Y, Steele SM. 2-octyl cyanoacrylate glue for the fixation of continuous peripheral nerve catheters. Anesthesiology 2003; 98:590-591.

45. Mattamal GJ. US FDA perspective on the regulations of medical-grade polymers: cyanoacrylate polymer medical device tissue adhesives. Expert Rev Med Devices 2008; 5:41-49. 